\title{
Emerging Trends in Mental Health Education - An Empirical Investigation
}

\section{Dr. Waseem Iqbal (M.B.B.S); Dr. Bakhtawar (M.B.B.S); Dr. Ruhma Farooqi (M.B.B.S)}

\begin{abstract}
:
Mental health education/literacy refers to the beliefs and knowledge regarding mental issues and disorders, aiding the management, recognition and/or prevention of these disorders in effective and efficient ways. The significance of mental health education/literacy has been investigated all over the world, unfortunately lacking focused in Pakistan therefore this study is aimed to identify and investigate emerging trends in mental health education/literacy and studied them in context of Pakistan. For this purpose, subject study identified literature related to the literacy in mental health through different databases; Cochrane, PubMed, PsycINFO, ScienceDirect, and LINSON, by using terms mental health literacy, emerging trends, emerging issues in mental health education/literacy. Study identified that there is limited and dearth knowledge regarding mental illness and treatments for mental illness among public. This review also highlights the importance of mental health literacy among professionals working in the field of health care. In Pakistan, due to low literacy rate, a high percentage of poverty and dearth of trained professionals warrants an emendation in approaches established for attaining the goal of public health and psychiatric care. Practical implications. Findings have implications for practitioners in the field of mental health care as well as designing targeted interventions for enhancing mental health literacy and help-seeking behavior in the future.
\end{abstract}

Keywords: Pakistan, Mental health literacy, Mental health, Review, Mental health perception 


\section{Introduction:}

Mental health is a major issue in both low- and middle-income countries (LMIC) (Kopinak, 2015; Katz et al., 2014; Ngui et al., 2010). Globally, the lifetime risk of the onset of mental health issues is more than 25 percent and the majority of the individuals are directly or indirectly influenced by these issues (Kessler et al., 2007). According to the results of the World Mental Health Survey, approximately 85 percent of severe mental health issues in LMIC received no therapeutic management during the past year (Ganasen et al., 2008). Worldwide, it is now perceived that adverse mental health is the cause of discrimination in society and a violation of human rights (Jiloha, 2010; Chua et al., 2019; Choudhry, Ming, Munawar, Zaidi, Patel, Khan and Elmer, 2019).

Increased rates of crimes are one of the ultimate results of low mental health literacy (Zimmerman et al., 2015). Likewise, low mental literacy is the cause of abuse in mental health care facilities which results in restraining or chaining patients with mental disorders (Michael et al., 2012). Since the last few years, mental health has remained a subject of debate in Pakistan (Naz and Khalily, 2016; Choudhry and Bokharey, 2013; Choudhry et al., 2017, 2018). In the background of growing terrorism, insecurity, constant poverty, stress, unemployment and disruption of the social fabric, the incidence and prevalence of mental health issues have increased tremendously (Gadit and Vahidy, 1999; Choudhry et al., 2016). In Pakistan, according to the estimates, there are approximately
12 percent cases of neuropsychiatric disorders and this is adding to the total disease burden (2008). According to the World Health Organization Assessment Instrument for Mental Health Systems (WHO-AIMS, 2009), only five psychiatric hospitals and 400 psychiatrists exist in the country for a population exceeding $180 \mathrm{~m}$ (World Health Organization, 2009).

In Pakistan, major psychological disorders include depression (which accounts for more than 30 percent of the population), schizophrenia and anxiety (Tassawar, 2014; Qadir et al., 2017; Ali and Gul, 2018; Munawar et al., 2017). Jorm et al. (1997) first used the term "Mental health literacy." It is defined "as knowledge and beliefs about mental disorders which aid their recognition, management or prevention" (Jorm, 2000; Bahrami et al., 2019). Mental health literacy comprises the skill of a person to identify mental health issues; information and beliefs regarding self-treatment; risk and causal factors; help-seeking; as well as mental health information (Jorm et al., 1997). The literacy rate of the total population of Pakistan is 54 percent, which according to the local definition refers to "anyone, aged 15 and above who can read and write" (CIA, 2010; Rehman et al., 2015). With this low literacy background, most of the people seek help from faith healers because they believe in supernatural causes of illness (Gadit, 2003; Munawar and Tariq, 2018). Presently, there is a paucity of available mental health facilities in Pakistan. A review of the mental health care system in Pakistan revealed that this 
scenario improved after the implementation of a new Mental Health Law, which replaced the Lunacy Act of 1912 on 20 February 2001. This represents the current concept of mental illnesses, treatment, rehabilitation and civil and human rights (Tareen and Tareen, 2016). However, in Pakistan, the budget fixed for mental health is less than 2 percent (Afridi, 2008; Rathod et al., 2017). Due to a limited number of psychiatrists and psychologists (one psychiatrist is hired for more than 10,000 people), poor conditions/facilities of Basic Health Units (BHU), the majority of patients visit traditional faith healers (Choudhry and Bokharey, 2013; Choudhry et al., 2017, 2018; Choudhry, Munawar, Akram, Al-Worafi, Bakrin, Tey, Jacob, Hing, Khan, Han and Kamal, 2019; Akbari et al., 2009).

According to an estimate, there are a total of 203.07 (per 100,000 populations) professionals offering services in various mental health institutes either privately or under government practice. The total number of psychiatrists offering services in outpatient facilities, community-based psychiatric inpatient units and mental hospitals are 141, 187 and 14, respectively (Bhugra et al., 2015). There are 342 psychiatrists, 478 psychologists, 3,145 social workers and 22 occupational therapists (Dinesh

\section{Method:}

In a narrative review, summarization of various primary studies is carried out so that one can draw conclusions in the form of a holistic interpretation (Jeffrey and Beaudry, 2016). This interpretation is guided by the experience of reviewer, prevailing
Bhugra et al., 2015). A study carried out in LMIC highlighted the inclination of psychiatric patients toward traditional healers and religious leaders and lesser compliance with medication. Such patients were found to believe in supernatural causes and witchcraft as causes of mental illnesses. The same scenario is present in Pakistan where native faith healers are sometimes the only mental health care providers (Ganasen et al., 2008; Karim et al., 2004).

A research study highlighted the need for collaboration between health care providers and traditional healers and the need to mutually study the mental health literacy of traditional healers and health care providers (Mcinnis and Merajver, 2011; Suleiman et al., 2017). The importance of health literacy for physical health is widely studied; however, the area of mental health literacy in Pakistan is still in its infancy and there is a scarcity of empirical studies on mental health literacy, hence mental health can be considered as a neglected area. This narrative review study will highlight the current status of mental health literacy in the country and provide a holistic picture of mental health literacy, needs, recommendations and interventions required to spread the awareness regarding mental health among masses.

theories and models (Kirkevold, 1997). A critical analysis of the literature in books, electronic or paper-based research articles is carried out in a narrative review (Rother, 2007). In the case of comprehensive topics, narrative reviews are the 
best choice (Collins and Fauser, 2005). Such articles comprise of publications explaining and discussing certain topics or themes state of the science theoretically or contextually. In such review articles, there is an absence of the databases types of methodological approaches that are used to carry out the review, criteria of evaluation to include articles during search of a database (Rother, 2007; Bernardo et al., 2004).

However, in this study authors have mentioned search terms and databases. A preliminary search of the literature is the initial step in order to conduct a narrative review (Polgar et al., 1995). Therefore, the author attempts to explore the literature to assess the published work on the area of interest (Elizabeth Depoy, 1993; Lang, 1998). This step assists the author in refining the topic and objective of the overview. This initial search also helps in of available research studies on the topic of interest. In case a similar study comes forth like that of an author then it is better for the author to either choose a slightly different topic or modify the emphasis of the objective. In case of absence of a published review on a similar topic then the author can establish the need for specific contribution (Elizabeth Depoy, 1993; Lang, 1998).

After the topic is refined, the next step involves critical evaluation and review of the topic. A successful narrative review should be based on these: give written information employing the vital aspects for a narrative review, should be structured, combine the existing evidence relating to the topic and deliver a clear message (Green et al., 2006). Relevant literature relating to mental health literacy was identified through various database searches. The three scientific databases searched were:

\section{Figure 1 Showing main and subordinate themes}

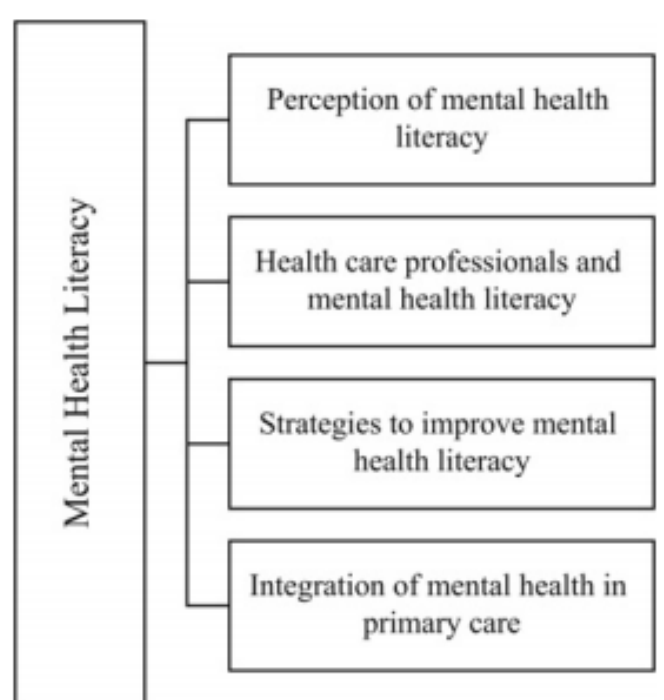

analyzing similar published studies. Furthermore, this search helps the author in assessing the number
PubMed, Cochrane Database of Systemic Reviews and PsycINFO using the terms mental health, 
mental health literacy, mental health education, Pakistan. The reference lists of the relevant articles were also manually scanned to identify other

\section{Results and discussion:}

\section{Perception of mental health literacy:}

Recognition is only a single characteristic of mental health literacy that impacts attitudes and behaviors about mental health issues. Contrary to mental health issues, there are lesser stigmas linked with physical illness. Due to this stigma, the individuals having various mental health issues report somatic complaints especially in regions where there is reduced mental health literacy (Lauber and Ro“ssler, 2007). In Pakistan, the empirical evidence shows a high prevalence of major depression or depressive symptoms (Muhammad Gadit and Mugford, 2007; Naeem et al., 2005; Qadir et al., 2014). Nevertheless, there is reduced knowledge in the Pakistani population regarding mental health issues. There is limited information available on knowledge and attitudes toward depressions and other mental illnesses.

In Pakistan, a majority of the cases, the faith healers/traditional healers/spiritual healers become the preferred and only providers of care related to mental health (Karim et al., 2004). Because the individuals in Pakistan prefer consulting faith healers, knowledge about different means of diagnosis and modes of treatment seems a necessary beginning point to include and consider these healers to further progress mental health literacy and adherence to treatment. One such research study explored the occurrence, related studies to be included in this review (Figure 1 showing the distribution of themes).

classification and treatment of mental health issues in Pakistani faith healers (Saeed et al., 2000). For mental health evaluations, the faith healers used "General Health Questionnaire" and "Psychiatric Assessment Schedule."

A little agreement existed between classification and diagnosis given by faith healers and DSM-IIIR; faith healers focused on supernatural causal factors of mental health issues. Faith healers used suggestions techniques and cultural psychotherapeutic procedures (Saeed et al., 2000). A study investigating knowledge and perception of patients regarding depression, its etiology and treatments, and views about non-pharmacological treatments showed that most of the patients described somatic complaints as influencing their functioning which leads them to seek medical treatment; for example, pain in the body, headache, sleep deprivation, weakness, vertigo, restlessness, etc. (Naeem et al., 2012). Other complaints comprised weeping, sadness and anger. Sadness as the main concern was reported by only a single patient out of four. When the patients were asked about their illness, they did not use any specific name for it and described it as some sort of physical illness and when asked if they heard about the word depression, none of them recognized it. However, when questioned if their diagnoses were physical or 
mental, the majority responded that it was a mental health issue.

Only a single patient mentioned physical illness. All the patients reported that mental health issues had influenced their functioning in daily life, but none of them had stopped performing their usual duties. Participants were also asked about knowledge of non-pharmacological treatments. A majority of participants denied consultation with any type of healer (i.e. faith healer, traditional healer, religious, etc.). This denial might be because the participants considered not to reveal their consultation with any type of healer outside the medical setup. Only one person mentioned the use of selfhelp treatment such as reading a verse from the Quran, doing dum (blowing incantation) and offering prayers (Naeem et al., 2012). Most of the participants were aware of psychiatrists and were not aware of any other professionals engaged in mental health care; only a few had heard of psychology as a profession.

A recent study conducted in Pakistan has shown a low awareness, however, the attitudes of participants toward mental illness were generally positive (Waqas et al., 2014). Most of the participants believed that superstitious things are a cause of mental health issues such as black magic, the evil eye, demonic possession and punishment from God but only a few believed that traditional healers/shamans could play a therapeutic role in treating mental illness. On contrary, a study showed that the residents of rural areas were much more likely to believe in superstitions and supernatural causes of mental health issues such as black magic and healing powers of Sufi shrines and talismans (Farooq and Kayani, 2012). The reasons reported during the study were experience, religion and tradition.

This shows an absence of trust in literate people regarding the therapeutic abilities of shamans or traditional healers as compared to people having low literacy level. Another study aimed at comparing British, British Pakistani and Native Pakistani medical students' beliefs about the manifestation, caused and cures of schizophrenia, before receiving any psychiatric training. A questionnaire was completed by a total of 305 participants on general beliefs about people with schizophrenia, casual explanation related to the cause of schizophrenia and the hospital and society roles in treating schizophrenia. There was stronger evidence suggesting that Pakistanis would have more negative attitudes and beliefs when compared with British and British Pakistanis, considering that people with schizophrenia tend to be more unpredictable and dangerous. Results revealed that there was no evidence which indicated that Pakistanis believed in more superstitious causal explanations. However, at the same time, Pakistanis were found to be more likely to seek help from faith healers, but not God. 


\section{Health care professionals and mental health literacy:}

Plenty of research studies have investigated mental health literacy in Pakistani health care professionals. A study investigating the knowledge and awareness about common mental health issues among general practitioners (GPs) in the private health setting showed that two-thirds of GPs lacked the knowledge of internationally recognized diagnostic criteria, i. e., International Classification of Diseases (ICD-10) criteria for major depression and anxiety disorders. For most of the mental health issues, most prescribed (75.3 percent) and common drugs were benzodiazepines (Naqvi et al., 2012). There were a very few GPs who were familiar with selective serotonin reuptake inhibitors, SSRIs (35.1 percent) or tricyclic antidepressants (20.2 percent). Some of the main barriers that hindered care-seeking were lack of time, lack of interest and patient's financial constraints.

Approximately 70 percent of GPs had not taken any current education about mental health issues during the past three years. In rural areas of Pakistan (where 66 percent of the population is residing) there is a scarcity of health care givers (Farooq et al., 2004). The majority of the psychiatric patients are seen by family doctors and alternate practitioners and 5-10 percent of the patients approach psychiatrists mainly due to stigma, low awareness level and cost issues (Gadit, 2007). Among other types of psychiatric services, there is almost a nonexistence of forensic psychiatry, very less number of child psychiatrists and hardly any number of psychiatrists for rehabilitation, addiction, geriatrics and liaison are available due to lack of training consultants (Gadit, 2006). A survey was conducted for assessing and comparing the knowledge and attitudes of major depression among medical and non-medical professionals and students in Pakistan. Approximately half of the participants revealed an absence of knowledge about major depression.

There was a significant proportion of participants who had a negative attitude toward patients suffering from depression (Husain et al., 2007). Likewise, another study revealed that various professionals differed in their perceptions toward taking medications and other medicines in the management of depression, psychotic disorders and people with no mental health issues. Findings revealed that very few nurses, social as well as occupational workers, were aware of standard methods of treatment, as compared to psychiatrists and psychologists.

A considerable number of health professionals recommended a psychologist or GP for the vignette that illustrated no symptoms of psychiatry, which showed a possible issue of overdiagnosis. The included studies demonstrate the need to upgrade the sharing of knowledge with the general population and primary health care professionals in Pakistan, as in many rural areas they are the first medical contact. The psychiatric conditions need a more prominent place in health education. This enhanced and improved mental health literacy can enable early diagnosis of mental health issues and adequate management, which can later decrease the negative 
outcomes associated with the illness that is left untreated.

\section{Strategies to improve mental health literacy:}

It is important to establish effective strategies that can help in improving mental health literacy in Pakistan. Awareness campaigns, training courses and educational workshops have been suggested (Jorm, 2000; Kitchener and Jorm, 2002). Kitchener and Jorm (2002) determined the effectiveness of the mental health first-aid training course for the improvement of mental health literacy in a workplace setting. Before undertaking the training, participants were randomized to either participate immediately or were wait-listed in the first-aid training course. The training course covered common health problems (such as depression, anxiety, psychosis and substance use) and mental health crises (e.g. suicide, acute psychotic behavior and panic attacks). It was found that this training program was effective in increasing mental health literacy among the public and revealed a broader application of these courses.

The high-income countries (i.e. the UK, USA and Norway) have launched various awareness campaigns targeted at the population level using all types of media and it has been a success (Jorm, 2000). Therefore, such awareness campaigns can also be launched in Pakistan especially in rural areas which would be effective in enhancing their mental health literacy. There has been a positive change in attitudes of secondary school students due to brief educational workshops (Pinfold et al., 2003). However, further studies are needed in LMIC to check the application and possibility of such methods in enhancing mental health literacy. Mental health literacy is a component of general literacy in LMIC and Pakistan has a literacy rate of less than 60 percent (2015). Therefore, it might be not suitable to adopt the abovementioned strategies solely due to their effectiveness in highincome countries (Mubbashar and Farooq, 2001).

Complete, extensive and advanced strategies should be adopted so that all the challenges can be met and all opportunities can be provided. Due to the presence of diverse cultural opinions related to mental illnesses in LMIC like Pakistan, more effective strategies can be developed and applied by understanding the perceptions of the population. To ensure the success of any strategy or plan related to increasing mental health literacy, it should incorporate recent advancements in mental health issues as well as also educate communities about currently acquired knowledge in the area. It is crucial to include all providers of mental health care in this plan, as many people consult alternate practitioners for issues related to mental health (Mirza et al., 2006). Moreover, along with providing access to various services related to mental health, cultural beliefs, family and educational background must be taken into consideration, and a foundation for mutual understanding between cultural-based and psychotherapeutic methods and evidence-based practices should also be established. 
In Pakistan, there is a need to amend approaches established for attaining the goal of public health and psychiatric care (Afridi, 2008). The drug abuse problem is increasing, and treatment is given by nonpsychiatric doctors to most of the patients. It will play a vital role in including more cases of drug abuse in the training program. In Pakistan, in most of cases, family members take care of the patients, therefore, workshops and pieces of training focused on community-based psychiatry and practices will be a vital step. Due to limited indigenous and cultural psychological therapies, most mental health professionals and psychologists use an eclectic approach. Presently, in Pakistan, no mental health care provider works in the national health system.
Interactive work with trained clinical psychologists may also be a crucial step in terms of counseling as well as psychotherapies.

Giving greater focus on psychotherapy, training will definitely contribute toward improving psychiatric care (2009). Keeping in view the social barriers such as stigma and belief system as well as professional barriers such as trained personnel and adequate services, there is a lack of active participation by government, donors and groups, patients and their families. Therefore, everyone should work together to enhance mental health services regarding prevention, treatment and rehabilitation (Afridi, 2008).

\section{Integration of mental health in primary care:}

Most of the research studies have suggested and advocated a strategy to increase literacy and at the same to increase services related to mental health care by providing training of professionals working in the field of primary health for dealing with common mental health issues (Goldberg, 1992; Petersen et al., 2000). Mental health training programs focused on integrating mental health into primary health care settings have been launched in various countries including Pakistan. These programs have been effective in providing mental health care to rural areas in countries where previously there was an absence of any mental health facilities (Petersen et al., 2000; Goldberg, 1992). In Pakistan, there is a need for more empirical data in this regard.
The current scenario in Pakistan about mental health demands undivided attention from many professionals linked to mental health practices including professional bodies, policymakers and academic personnel to review the policies for the development of joint mental health policy at the national level (Khalily, 2010). For the provision of cost-effective psychiatric services, accurate employment of present facilities is essential to reduce the capital expenditure. The health care system of Pakistan at present constitutes of both primary (BHU/Rural Health Center) and secondary care systems (District Head Quarter Hospitals and Teaching Hospitals) (Khalily, 2011). Appropriate training of health care professionals, in psychiatry, can lead to an improvement in the provision of 
mental health services in terms of well-timed diagnosis, adequate treatment and consultation to specialty services (Chisholm et al., 2000; Gater, 2001).

National health policy can be collaboratively formulated by the consensus of professional bodies (Pakistan Association for Mental Health and Pakistan Association for Clinical Psychologists) and other organizations. Currently, in Pakistan, no standardized professional education system is available for a thorough understanding of mental health problems at the university level (Khalily, 2010). Mental health is a serious public health dilemma and needs a competency center to conduct various short term and doctorate level courses at the university with special prominence to neuropsychological disorders and traumas, and addiction. Based on socio-cultural norms of society, females shall be encouraged to undertake postgraduate training of mental health (Niaz, 2004; Miller and Rasco, 2004).

Actions for global mental health (Patel et al., 2011) and media participation would be important in improving mental health (Joop, 2006). Print media has always portrayed negative aspects of mental disorders and has resulted in a stereotypic

\section{Study limitations:}

This study was limited to published journal articles in English, and only those available in a few databases. There could be other gray literature assessing mental health literacy that was excluded. understanding of mental illness (Wahl, 2003; Coverdale et al., 2002). One of the causes of this negative depiction is low mental health literacy among journalists (Allen and Nairn, 1997). In an attempt to promote mental health services Pakistan has adopted the approach of educating various professionals engaged in the activities of providing such services (Mirza et al., 2006; Goldberg, 1992). School children are a proven source to increase the health literacy of the rest of the community whereas education of conventional practitioners resulted in pinpointing and signposting the individuals with mental disorders to appropriate professionals (Rahman et al., 1998).

In LMIC, the provision of internet facility has not only aggravated existing health disparities, the flood of information and transmission of ambiguous information but has also provided communication means and assisted in locating health education insufficiencies (Gray et al., 2005). It can also serve as a medium to promote expertise in health literacy in the younger generation. The internet shall be used to promote health in coalition with health care professionals and training programs (Cline and Haynes, 2001).

Furthermore, the quality of the included studies was also not assessed. Hence, a more a systematic review following PRISMA, to overcome the 
limitations of this review, may be conducted to include studies that may have been overlooked.

\section{Conclusion:}

Due to the global pervasiveness of mental disorders, it can be deduced that substantial efforts are required in Pakistan to improve the current scenario of mental health education. Insufficiencies in mental health education and inadequate availability of mental health facilities notably augment economic disparities and increase the burden of disease thereby hampering the rationale care of the ailing population. Nevertheless, such connections shall be closely studied. Multidisciplinary and unconventional approaches are adopted to address challenges like lack of education, insufficient organizational structures, economic curtailments and poor policy reinforcements. This is pivotal in the instance that mental health policymakers have insufficient knowledge about mental disorders. Besides, to gain familiarity with a vast variety of mental health ailments, it is crucial for a multitude of personnel including health care providers and professionals like conventional practitioners, paramedics and police to come across a person with mental illness.

Perhaps it may be consequent on confusion and general stigma surrounding mental illness. Public mandate, interactive health care system tending to illness and educated society in mental disorders entailed to identification, disease prevention and timely access to a health care facility for treatment of mental disorders. Furthermore, innovative strategies need to be adopted in community settings to create public awareness of mental disorders and finally, an assessment of intervention to provide positive outcomes in terms of mental health developments. 


\section{References:}

Afridi, M.I. (2008), "Mental health: priorities in Pakistan”, Journal of Pakistan Medical Association, Vol. 5 No. 5, pp. 225-6, available at: http://jpma.org.pk/full article text.php?article $\mathrm{id}=1386$

Akbari, A.H., Rankaduwa, W. and Kiani, A.K. (2009), "Demand for public health care in Pakistan", The Pakistan Development Review, Vol. 48 No. 2, pp. 141-53.

Ali, T.M. and Gul, S. (2018), "Community mental health services in Pakistan: review study from Muslim World 2000-2015”, Psychology, Community \& Health, Vol. 7 No. 1, pp. 57-71.

Allen, R. and Nairn, R.G. (1997), "Media depictions of mental illness: an analysis of the use of dangerousness", Australian and New Zealand Journal of Psychiatry, Vol. 31 No. 3, pp. 375-81.

Bahrami, M.A., Bahrami, D. and Chaman-Ara, K. (2019), “The correlations of mental health literacy with psychological aspects of general health among Iranian female students", International Journal of Mental Health Systems, Vol. 13, pp. 59-65.

Bernardo, W.M., Nobre, M.R.C. and Jatene, F.B. (2004), “A pra'tica clı'nica baseada em evide^ncias: parte II - buscando as evide^ncias em fontes de informac „ão”, Revista da Associac,ão Me'dica Brasileira, Vol. 50 No. 1 , pp. 104-8.

Bhugra, D., Tse, S., Ng, R. and Takei, N. (2015), Routledge Handbook of Psychiatry in Asia, Routledge, New York, NY.

Chisholm, D., James, S., Sekar, K., Kumar, K.K., Murthy, R.S., Saeed, K. and Mubbashar, M. (2000), "Integration of mental health care into primary care", The British Journal of Psychiatry, Vol. 176, pp. 5818.

Choudhry, F.R. and Bokharey, I.Z. (2013), "Perception of mental health in Pakistani nomads: an interpretative phenomenological analyses", International Journal of Qualitative Studies on Health and WellBeing, Vol. 8 No. 1, p. 22469.

Choudhry, F.R., Khan, T.M., Park, M.S.-A. and Golden, K.J. (2018), "Mental health conceptualization and resilience factors in the Kalasha youth: an indigenous ethnic and religious minority community in Pakistan", Frontiers in Public Health, Vol. 6, p. 6.

Choudhry, F.R., Mani, V., Ming, L.C. and Khan, T.M. (2016), "Beliefs and perception about mental health issues: a meta-synthesis", Neuropsychiatric Disease and Treatment, Vol. 12, pp. 2807-18. 
Choudhry, F.R., Park, M.S.-A., Golden, K. and Bokharey, I.Z. (2017), "'We are the soul, pearl and beauty of Hindu Kush Mountains': exploring resilience and psychological wellbeing of Kalasha, an ethnic and religious minority group in Pakistan", International Journal of Qualitative Studies on Health and Wellbeing, Vol. 12 No. 1.

Choudhry, F.R., Ming, L.C., Munawar, K., Zaidi, S.T.R., Patel, R.P., Khan, T.M. and Elmer, S. (2019), "Health literacy studies conducted in Australia: a scoping review", International Journal of Environmental Research and Public Health, Vol. 16 No. 7, p. 1112.

Choudhry, F., Munawar, K., Akram, B., Al-Worafi, Y., Bakrin, F., Tey, L., Jacob, S., Hing, G., Khan, T., Han, L. and Kamal, A. (2019), "Xylophagia: a meta-synthesis of the literature”, Mental Health Review Journal, Vol. 24 No. 4, pp. 275-97, available at: https://doi. org/10.1108/MHRJ-01-2019-0005

Chua, R.Y., Kadirvelu, A., Yasin, S., Choudhry, F.R. and Park, M.S.A. (2019), "The cultural, family and community factors for resilience in Southeast Asian indigenous communities: a systematic review", Journal of Community Psychology, Vol. 47 No. 7, pp. 1750-71.

CIA (2010), The World Factbook, 2010 ed. (CIA’s 2009 ed.), Potomac Books, Washington, DC. Cline, R.J. and Haynes, K.M. (2001), "Consumer health information seeking on the internet: the state of the art", Health Education Research, Vol. 16 No. 6, pp. 671-92.

Collins, J.A. and Fauser, B.C.J.M. (2005), "Balancing the strengths of systematic and narrative reviews", Human Reproduction Update, Vol. 11 No. 2, pp. 103-4.

Coverdale, J., Nairn, R. and Claasen, D. (2002), "Depictions of mental illness in print media: a prospective national sample", Australian and New Zealand Journal of Psychiatry, Vol. 36 No. 5, pp. 697-700.

Dinesh Bhugra, S.T., Roger, N.G. and Takei, N. (2015), Routledge Handbook of Psychiatry in Asia, Routledge, Abingdon. Elizabeth Depoy, L.N.G. (1993), Introduction to Research: Understanding and Applying Multiple Strategies, Mosby-Year Book, St. Louis, MO. Farooq, A. and Kayani, A.K. (2012), "Prevalence of superstitions and other supernaturals in rural Punjab: a sociological perspective", South Asian Studies, Vol. 27 No. 2, p. 335.

Farooq, U., Ghaffar, A., Narru, I.A., Khan, D. and Irshad, R. (2004), "Doctors perception about staying in or leaving rural health facilities in district Abbottabad", Journal of Ayub Medical College Abbottabad, Vol. 16 No. 2, pp. 64-9. 
Gadit, A. (2003), "Healthcare service delivery by shamans", International Journal of Mental Health, Vol. 32 No. 2, pp. 63-83. Gadit, A. (2006), “Mental health in Pakistan: where do we stand?”, Journal of Pakistan Medical Association, Vol. 56 No. 5, pp. 198-9.

Gadit, A. and Vahidy, A. (1999), "Mental health morbidity pattern in Pakistan", Journal of College Physicians and Surgeons Pakistan, Vol. 9, pp. 362-65.

Gadit, A.A. (2007), "Psychiatry in Pakistan: 1947-2006: a new balance sheet”, JPMA, Vol. 57 No. 9, pp. 453-62.

Ganasen, K.A., Parker, S., Hugo, C.J., Stein, D.J., Emsley, R.A. and Seedat, S. (2008), "Mental health literacy: focus on developing countries", African Journal of Psychiatry (Johannesbg), Vol. 11 No. 1, pp. 23-8.

Gater, G. (2001), "Mental health and service development in Pakistan. Mental health in the new millennium: Freud, freedom and future", in Mubashar, M.H. and Humayun, A. (Eds), Proceedings of the 13th International Psychiatric Conference, Rawalpindi Institute of Psychiatry, pp. 356-68.

Goldberg, D. (1992), “India, Pakistan: community psychiatry”, The Lancet, Vol. 339, pp. 114-15. Gray, N.J., Klein, J.D., Noyce, P.R., Sesselberg, T.S. and Cantrill, J.A. (2005), “The internet: a window on adolescent health literacy", Journal of Adolescent Health, Vol. 37 No. 3, pp. 243.e1-243.e7.

Green, B.N., Johnson, C.D. and Adams, A. (2006), "Writing narrative literature reviews for peer-reviewed journals: secrets of the trade", Journal of Chiropractic Medicine, Vol. 5 No. 3, pp. 101-17.

Husain, N., Chaudhry, I.B., Afridi, M.A., Tomenson, B. and Creed, F. (2007), "Life stress and depression in a tribal area of Pakistan”, British Journal of Psychiatry, Vol. 190, pp. 36-41.

Jeffrey, S. and Beaudry, L.M. (2016), Research Literacy: A Primer for Understanding and Using Research, Guilford Publications, New York, NY.

Jiloha, R.C. (2010), "Deprivation, discrimination, human rights violation, and mental health of the deprived", Indian Journal of Psychiatry, Vol. 52 No. 3, pp. 207-12.

Joop, D.J. (2006), Trauma, War, and Violence: Public Mental Health in Socio-Cultural Context, Springer Sciencep Business Media, New York, NY.

Jorm, A. (2000), "Mental health literacy: public knowledge and beliefs about mental disorders", British Journal of Psychiatry, Vol. 177, pp. 396-401. 
Jorm, A.F., Jacomb, K.A., Christensen, P.A., Rodgers, H. and Pollitt, P.B. (1997), “'Mental health literacy’: a survey of the public's ability to recognise mental disorders and their beliefs about the effectiveness of treatment", MJA, Vol. 166 No. 4, pp. 182-6.

Karim, S., Saeed, K., Rana, M.H., Mubbashar, M.H. and Jenkins, R. (2004), "Pakistan mental health country profile", International Review of Psychiatry, Vol. 16 Nos 1-2, pp. 83-92.

Katz, C.L., Lahey, T.P. and Campbell, H.T. (2014), “An ethical framework for global psychiatry”, Annals of Global Health, Vol. 80 No. 2, pp. 146-51.

Kessler, R.C., Amminger, G.P., Aguilar-Gaxiola, S., Alonso, J., Lee, S. and Ustun, T.B. (2007), “Age of onset of mental disorders: a review of recent literature", Current Opinion in Psychiatry, Vol. 20 No. 4, pp. 359-64.

Khalily, M.T. (2010), "Developing a coordinated response to drug abuse in Pakistan", Journal of Interprofessional Care, Vol. 24 No. 2, pp. 168-72.

Khalily, M.T. (2011), "Mental health problems in Pakistani society as a consequence of violence and trauma: a case for better integration of care", International Journal of Integrated Care, Vol. 11 No. 4, p. 11.

Kirkevold, M. (1997), "Integrative nursing research - an important strategy to further the development of nursing science and nursing practice”, Journal of Advance Nursing, Vol. 25 No. 5, pp. 977-84.

Kitchener, B.A. and Jorm, A.F. (2002), "Mental health first aid training for the public: evaluation of effects on knowledge, attitudes and helping behavior”, BMC Psychiatry, Vol. 2 No. 1, p. 10.

Kopinak, J.K. (2015), "Mental health in developing countries: challenges and opportunities in introducing western mental health system in Uganda", International Journal of MCH and AIDS, Vol. 3 No. 1, pp. 2230.

Lang, H.G. (1998), A Practical Guide to Research Methods, University Press of America, Lanham, MD. Lauber, C. and Ro"ssler, W. (2007), "Stigma towards people with mental illness in developing countries in Asia”, International Review of Psychiatry, Vol. 19 No. 2, pp. 157-78.

Mcinnis, M.G. and Merajver, S.D. (2011), "Global mental health: global strengths and strategies: taskshifting in a shifting health economy”, Asian Journal of Psychiatry, Vol. 4 No. 3, pp. 165-71.

Michael, H., Merson, R.E.B. and Anne, J.M. (2012), Global Health, Jones \& Bartlett Publishers, Sudbury. Miller, K.E. and Rasco, L.M. (2004), The Mental Health of Refugees: Ecological Approaches to Healing and Adaptation, Taylor \& Francis, 
Mahwah, NJ. Mirza, I., Mujtaba, M., Chaudhry, H. and Jenkins, R. (2006), "Primary mental health care in rural Punjab, Pakistan: providers, and user perspectives of the effectiveness of treatments", Social Science \& Medicine, Vol. 63 No. 3, pp. 593-7.

Mubbashar, M. and Farooq, S. (2001), "Mental health literacy in developing countries", The British Journal of Psychiatry, Vol. 179 No. 1, p. 75.

Muhammad Gadit, A.A. and Mugford, G. (2007), "Prevalence of depression among households in three capital cities of Pakistan: need to revise the mental health policy”, PLoS One, Vol. 2 No. 2, p. e209.

Munawar, K. and Tariq, O. (2018), "Exploring relationship between spiritual intelligence, religiosity and life satisfaction among elderly Pakistani Muslims”, Journal of Religion and Health, Vol. 57 No. 3, pp. 78195.

Munawar, K., Bokharey, I.Z. and Choudhry, F.R. (2017), "Sexual conflicts in panic disorder: a multi-case study”, Mental Health Review Journal, Vol. 22 No. 4, pp. 300-14.

Naeem, F., Ayub, M., Kingdon, D. and Gobbi, M. (2012), "Views of depressed patients in Pakistan concerning their illness, its causes, and treatments", Qualitative Health Research, Vol. 22 No. 8, pp. 108393.

Naeem, F., Ayub, M., Izhar, N., Javed, Z., Irfan, M., Haral, F. and Kingdon, D. (2005), "Stigma and knowledge of depression: a survey comparing medical and non-medical students and staff in Lahore, Pakistan", Pakistan Journal of Medical Science, Vol. 21 No. 2, pp. 155-8.

Naqvi, H., Sabzwari, S., Hussain, S., Islam, M. and Zaman, M. (2012), “General practitioners' awareness and management of common psychiatric disorders: a community-based survey from Karachi, Pakistan", Eastern Mediterranean Health Journal, Vol. 18 No. 5, pp. 446-53.

Naz, S. and Khalily, M.T. (2016), "Indigenous adoption of Novaco's model of anger management among individuals with psychiatric problems in Pakistan", Journal of Religion and Health, Vol. 55 No. 2, pp. 43947.

Ngui, E.M., Khasakhala, L., Ndetei, D. and Roberts, L.W. (2010), "Mental disorders, health inequalities and ethics: a global perspective", International Review of Psychiatry (Abingdon, England), Vol. 22 No. 3 , pp. $235-44$.

Niaz, U. (2004), “Women's mental health in Pakistan”, World Psychiatry, Vol. 3 No. 1, p. 60. 
Patel, V., Collins, P.Y., Copeland, J., Kakuma, R., Katontoka, S., Lamichhane, J., Naik, S. and Skeen, S. (2011), "The movement for global mental health", The British Journal of Psychiatry, Vol. 198 No. 2, pp. 88-90.

Petersen, I., Bhagwanjee, A. and Parekh, A. (2000), "From policy to praxis - a framework for the delivery of district mental health care in KwaZulu-Natal", South African Medical Journal-Cape Town-Medical Association of South Africa, Vol. 90 No. 8, pp. 798-803.

Pinfold, V., Toulmin, H., Thornicroft, G., Huxley, P., Farmer, P. and Graham, T. (2003), "Reducing psychiatric stigma and discrimination: evaluation of educational interventions in UK secondary schools", The British Journal of Psychiatry, Vol. 182 No. 4, pp. 342-6.

Polgar, S., Thomas and Shane, A. (1995), Introduction to Research in the Health Sciences, Churchill Livingstone, Melbourne and New York, NY.

Qadir, F., Haqqani, S., Khalid, A., Huma, Z. and Medhin, G. (2014), "A pilot study of depression among older people in Rawalpindi, Pakistan”, BMC research notes, Vol. 7 No. 1, pp. 409-17.

Qadir, T.F., Fatima, H., Hussain, S.A. and Menezes, R.G. (2017), "Criminal responsibility and mental illness in Pakistan", The Lancet Psychiatry, Vol. 4 No. 2, pp. 97-8.

Rahman, A., Mubbashar, M., Gater, R. and Goldberg, D. (1998), "Randomised trial of impact of school mental-health programme in rural Rawalpindi, Pakistan”, The Lancet, Vol. 352, pp. 1022-5.

Rathod, S., Pinninti, N., Irfan, M., Gorczynski, P., Rathod, P., Gega, L. and Naeem, F. (2017), "Mental health service provision in low- and middle-income countries", Health Services Insights, Vol. 10, pp. 1-7. Rehman, A., Jingdong, L. and Hussain, I. (2015), "The province-wise literacy rate in Pakistan and its impact on the economy", Pacific Science Review B: Humanities and Social Sciences, Vol. 1 No. 3, pp. 140-4.

Rother, E.T. (2007), "Revisão sistema'tica X revisão narrativa”, Acta Paulista de Enfermagem, Vol. 20 No. 2, pp. v-vi.

Saeed, K., Gater, R., Hussain, A. and Mubbashar, M. (2000), "The prevalence, classification and treatment of mental disorders among attenders of native faith healers in rural Pakistan", Social Psychiatry and Psychiatric Epidemiology, Vol. 35 No. 10, pp. 480-5.

Suleiman, A.K., Ismadi, N.F.I., Choudhry, F.R., Munawar, K. and Hameed, M.A. (2017), "Determinant factors of depression: a survey among university students", Malaysian Journal of Public Health Medicine, Vol. 17 No. 3, pp. 97-103. 
Tareen, A. and Tareen, K.I. (2016), "Mental health law in Pakistan”, BJPsych International, Vol. 13 No. 3 , pp. 67-9.

Tassawar (2014), "The communicative initiative network", Mental Health crises in Pakistan, available at: www.comminit.com/global/content/mental-health-crises-pakistan(accessedNovember 22, 2019).

Wahl, O.F. (2003), "News media portrayal of mental illness: implications for public policy", American Behavioral Scientist, Vol. 46 No. 12, pp. 1594-600. Waqas, A., Zubair, M., Ghulam, H., Ullah, M.W. and Tariq, M.Z. (2014), "Public stigma associated with mental illnesses in Pakistani university students: a cross sectional survey", PeerJ, Vol. 2, p. e698. WHO-AIMS (2009), "WHO-AIMS report on mental health system in Pakistan", Ministry of Health Pakistan, available at: www.who.int/mental_health/pakistan_who_aims_report.pdf(accessedNovember 22, 2019). World Health Organization (2009), "WHO-AIMS report on mental health system in Pakistan", available at: www.who.int/mental_health/pakistan_who_aims_report.pdf(accessedNovember 22, 2019). Zimmerman, E.B., Woolf, S.H., Haley, A., Kaplan, R.M., Spittel, M.L. and David, D.H. (2015), Population Health: Behavioral and Social Science Insights, US HHS: Agency for Healthcare Research and Quality, US Department of Health \& Human Services, available at: www.ahrq.gov/professionals/education/ curriculumtools/population-health/zimmerman.html(accessedNovember 21, 2019). 